\title{
Reconstruction of esthetically compromised maxillary anterior teeth with CAD CAM zirconia crowns - A case report
}

Manawar Ahmad ${ }^{1 *}$, Hina Naim¹, Hussain Hadi Hussain AlSagoor ${ }^{2}$, Mohammad Ali Zailai Alomar², Ali Mohammed Bakri Madkhali², Abdullah Hussein Ahmed AlAsmari ${ }^{2}$ and Yasser Abdullah Hummedi ${ }^{2}$

${ }^{1}$ Assistant Professor, Department of Prosthetic Dental Sciences, College of Dentistry, Jazan University, Saudi Arabia

${ }^{2} \mathrm{BDS}$ student, 6th year, College of Dentistry, Jazan University, Saudi Arabia

\begin{abstract}
The advancement of new technologies for the creation of biomaterials has been inspired by the demand for materials, capable of bearing new specifications and applications. Ceramic materials based on alumina (A12O3) and zirconia $(\mathrm{ZrO} 2)$ is used as material of choice for fixed dental prosthesis due to their excellent properties, such as strength, corrosion resistance and biocompatibility. Full coverage zirconia- based ceramic crowns with knife edge preparations can offer a good esthetic result with minimum tooth preparation combining strength and could be considered as a treatment option in selected clinical cases. All-ceramic frameworks are fabricated from zirconium oxide and veneered in the layering technique. Additional advantages of the zirconia based all ceramic restorations are the esthetic characteristics, the biocompatibility and durability. They also show increased abrasion resistance, color and contour stability, appropriate translucency and excellent tissue response due to minimal plaque accumulation.
\end{abstract}

\section{Introduction}

The name "Zirconium" is derived from Arabic word "Zargon" which means 'golden' in colour. Zirconium dioxide $(\mathrm{ZrO} 2)$ was first identified by a German chemist Martin Heinrich Klaproth in 1789 [1]. The transformation toughened Zirconia has unique properties such as high fracture toughness and strength. Zirconium is a polycrystalline ceramic without any glass component. It is a polymorph that occurs in three forms, monoclinic (M), cubic (C) and tetragonal (T). To achieve an esthetic result with conventional porcelain fused to metal crown or all ceramic crowns, an extensive tooth preparation is required that might lead to endodontic therapy, increased cost and time- consuming laboratory procedures. Furthermore, some common complications such as cracking, chipping and the fracture of the veneering porcelain material can also reduce the longevity of the restoration [2].

These restorations combine the mechanical strength of all ceramic crowns and the esthetic performance of veneers with minimal preparation at the cervical areas. Zirconia crowns ensure optimum esthetic result with increased strength on the cervical areas. It produces consistent quality and superior marginal fit [3]. It does not require very complicated clinical procedures. Extensive in vitro and in vivo studies have confirmed its high fracture resistance and its use in both stress bearing areas as well as esthetic non stress bearing area.

\section{Case report}

A 26 years old male patient came with the chief complaint of mutilated and unpleasing maxillary anterior teeth that had been restored repeatedly in the past with direct resin composite restorations (Figure 1). Intra oral examination showed the showed inadequate shaped and discolored restorations with numerous cracks in the marginal areas of the tooth number $\# 11,12,21,22$, and 23 . There was marginal gingival inflammation present despite the good level of the oral hygiene due to inadequate emergence profile and over contoured existing restorations. All anterior teeth were non vital with endodontic treatment. Intra oral periapical radiograph revealed unsatisfactory incomplete obturation of the previously root canal treated tooth \#11, 12, 21, 22, 23 (Figure 2). The final treatment plan for the patient included the correction of previously root canal treated teeth with re-obturation of the canal, fabrication of post and core and zirconia crowns for all the maxillary anterior teeth. Considering the patient's age, profession and his interest and awareness about the latest available restorative material, zirconia restoration was chosen to restore all the maxillary anterior crowns to fulfill the patient's esthetic and functional demands and to boost his confidence towards life.

After the clinical examination, primary alginate impressions were taken and study casts were fabricated. Face bow transfer was made and maxillary and mandibular casts were mounted on the semi adjustable articulator (Figure 3). A full wax-up of all maxillary anterior teeth was accomplished to evaluate the final treatment outcome. The existing gutta percha was removed from the improperly obturated root canal of previously treated maxillary anterior teeth. Then root canal

Correspondence to: Manawar Ahmad, Assistant Professor, Department of Prosthetic Dental Sciences, College of Dentistry, Jazan University, Saudi Arabia, E-mail: ahmad955mls@gmail.com

Key words: CAD/CAM restorations, porcelain fused to metal crowns, all ceramic crown, zirconia crowns

Received: April 16, 2017; Accepted: April 26, 2017; Published: April 29, 2017 


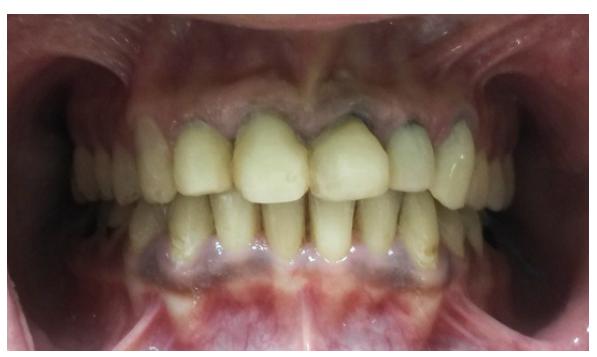

Figure 1: Pre-operative intra oral frontal view.

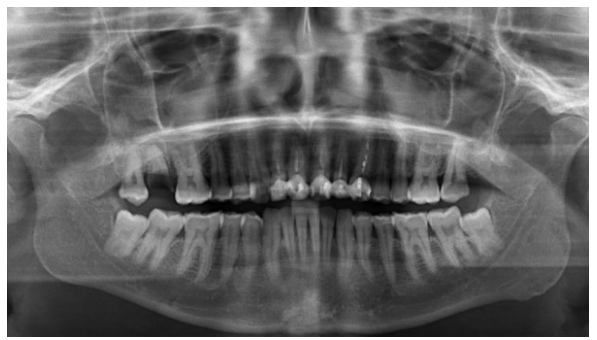

Figure 2: OPG showing unsatisfactory root canal treatment.

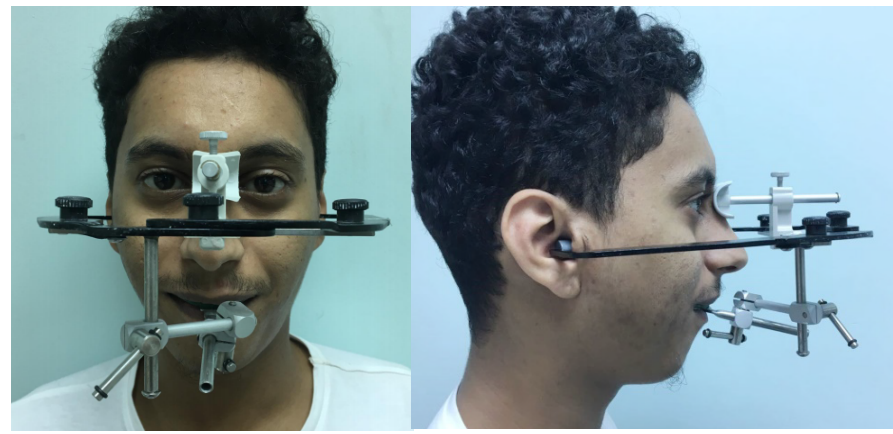

Figure 3: Face bow transfer frontal and lateral view.

treatment was repeated with satisfactory obturation of the individual canals. Due to insufficient remaining tooth structure for the retention of the crowns, fibre posts were cemented to the tooth \#11,12, 21, 22 and 23 with dual cure resin cement (Figure 4). Core build up was accomplished with composite resin. The crown lengthening procedure was carried out along with osteotectomy to achieve the desired crown height. After the healing period of 6 weeks, tooth preparation for zirconia crowns was done for all the maxillary anterior teeth from canine to canine. The axial reduction of approximately 1.2 to $1.5 \mathrm{~mm}$ and incisal reduction of 1.5 to $2.0 \mathrm{~mm}$ was carried out following the manufacturer's guidelines. All the line angles and point angles were rounded off with the taper of 5 to 15 degree. A heavy chamfer finish line was prepared circumferentially for all the individual teeth [4]. The occlusal clearance was kept 1.5 to $2 \mathrm{~mm}$ which was verified using red modeling wax (Figure 5). Retraction cord of size \#00 was placed in the gingival sulcus to record the finish line properly in the final impression (Figure 6). Secondary impression was made using addition poly vinyl siloxane impression material with double mix single stage impression technique. Provisional crowns were fabricated using tooth colored auto polymerizing acrylic resin and cemented with eugenol free temporary cement to the patient (Figure 7).

The secondary impression was poured with Type V Dental stone and master cast with removable individual dies were fabricated. The scanning of each individual prepared die was done with a CAD/CAM machine using the digital wax knife software. The final data was fed with the milling machine using the same design software and six zirconia copings were milled (Figure 8). Zirconia copings try-in was done in the patient's mouth and checked for any occlusal interference (Figure 9). After the coping is tried for the fit in patient's mouth the porcelain layers were added on the zirconia coping (Figure 10). After the occlusal evaluation in centric and eccentric positions, all six zirconia crowns were cemented with dual cure resin bonded cement (Figure 11). Compressive strength of zinc phosphate is cement is $104 \mathrm{MPa}$, for glass ionomer it ranges from 53-96 MPa and for dual cure resin cement it ranges from52-224 MPa [5]. First the crowns were etched with hydrofluoric acid and then silane coupling agent was applied and then air dried on each individual crown. The tooth surface was also etched and air dried. Resin bonded glass ionomer cement and zinc phosphate can also be used for cementation. Patient was recalled after one week. Patient was not only highly satisfied with the shape and size

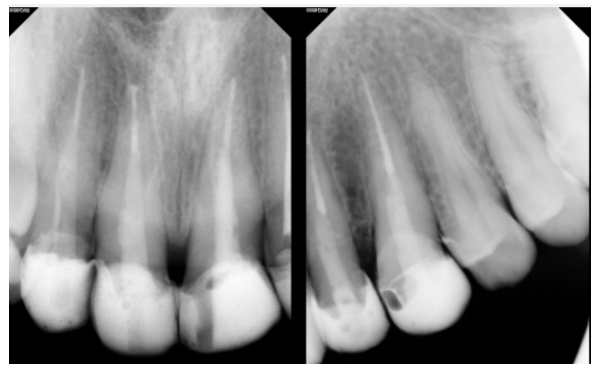

Figure 4: IOPA with fiber post \& core in maxillary anterior.

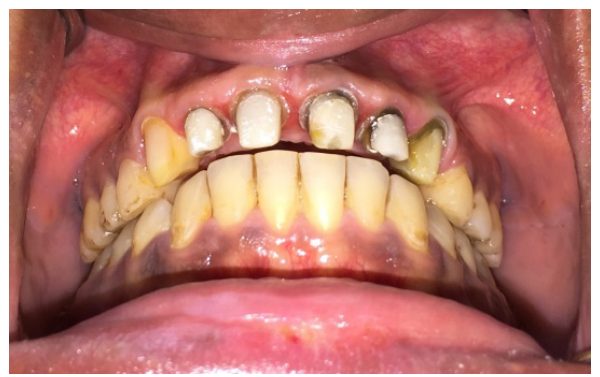

Figure 5: Tooth preparation with adequate incisal clearance.

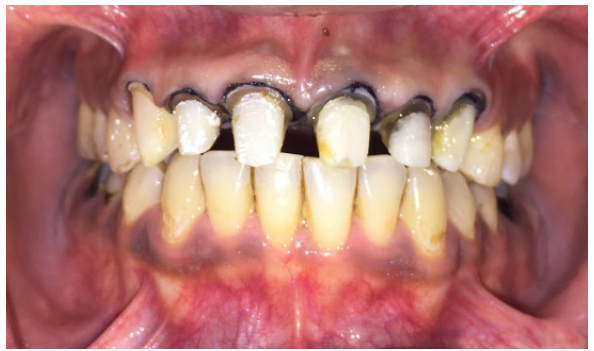

Figure 6: Retraction cord placement before final impression

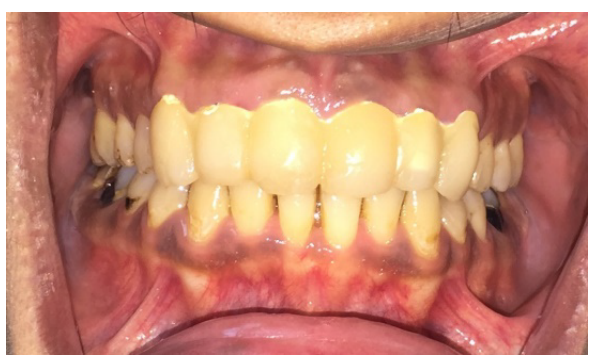

Figure 7: Provisional restoration on maxillary anterior. 


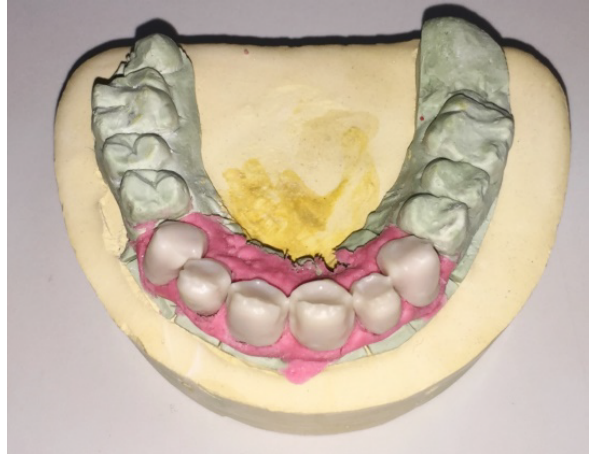

Figure 8: CAD-CAM zirconia copings.

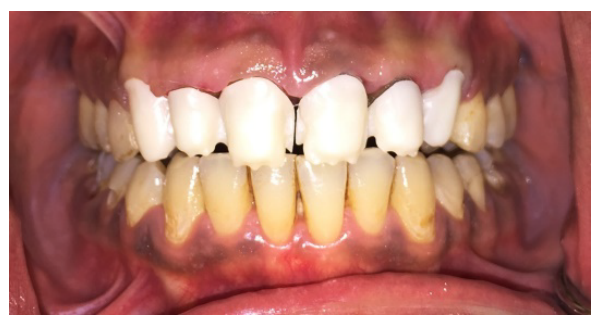

Figure 9: Coping try-in for maxillary anterior.

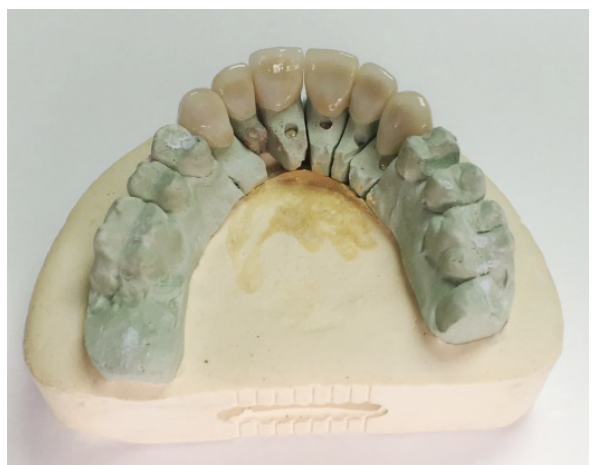

Figure 10: Porcelain Layering of zirconia copings.

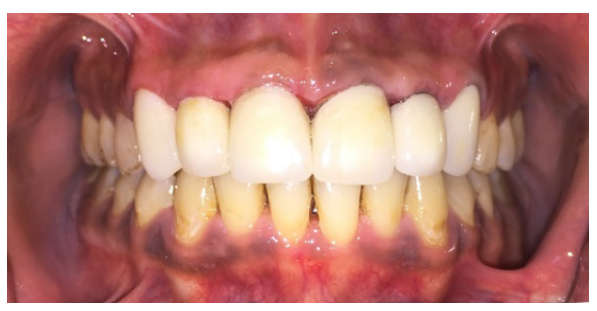

Figure 11: Cementation of zirconia crowns.

of the anterior teeth but also extremely happy about the final esthetic result that demanded to be natural looking (Figures 12 and 13).

\section{Discussion}

Zirconium is a strong grayish-white, soft, ductile, and malleable transition metal that mainly obtained from the mineral called zircon. Zirconium dioxide is present as monoclinic or tetragonal phases. At room temperature only the monoclinic $\mathrm{ZrO} 2$ exists. This phase is stable up to $1170^{\circ} \mathrm{C}$ when it inverts to a tetragonal, metastable phase, whereas above $2370^{\circ} \mathrm{C}$ it turns into a cubic phase [6,7]. Pure zirconia cannot be used in the fabrication of constituents, deprived of the addition of stabilizers such as Yittrium oxide. Yttrium tetragonal Zirconia polycrystals (Y-TZP) based systems are the recent addition to the high-strength all-ceramic systems that are used for crowns and fixed partial dentures. CAD/CAM produced Y-TZP based systems are used in the aesthetic zone and in stress bearing regions. Partially stabilized zirconia is highly resistant to corrosion by alkalis, acids, salt water, and any other food ingradients. It has a high flexural strength of more than $1000 \mathrm{MPa}$ and Hardness of 1200-1400 Vickers.

Zirconium dioxide $(\mathrm{ZrO} 2)$ is used to fabricate prosthodontic restorations such as single crown, bridges, veneers, inlay, onlay, endodontic posts as well as Zirconia abutments for implants. Distortion of zirconia framework is very minimum during the firing procedure of the porcelain. There is no plaque accumulation on the surface of zirconia crowns because zirconium ceramic does not react to the protein in saliva.

Numerous clinical studies show that cohesive fracture of the veneer material is the main limitation of its use for fixed restoration $[8,9]$. Regarding the available literature and some short-term clinical trials, core fractures were noticeably rare reported in zirconia-based single crowns over 1 to 3 years of follow up, while the veneer fracture proportion ranged from $0 \%$ to $15 \%[10,11]$. The incidence of chipping on zirconia based fixed restoration has been reported ranging from $0 \%$ to $4 \%$ in clinical studies with 20 to 60 months follow-up [12-14]. Other limitations are special Milling center is required for the scanning and processing, this phase of production is, to some degree, tedious. Case details such as framework thickness, configuration and shade may be specified in a script and sent to the milling center to achieve the desired restorative goals. It is a very hard substance to adjust if occlusal premature contacts exist during cementation procedure.

\section{Conclusion}

Excellent material physical properties, biocompatibility, and superior aesthetics make Y-TZP a popular material among the contemporary all-ceramic material. By eliminating the conventional lab procedures and utilizing the simplified high technology CAD-CAM technique it can definitely satisfy critical aesthetic needs of the patients

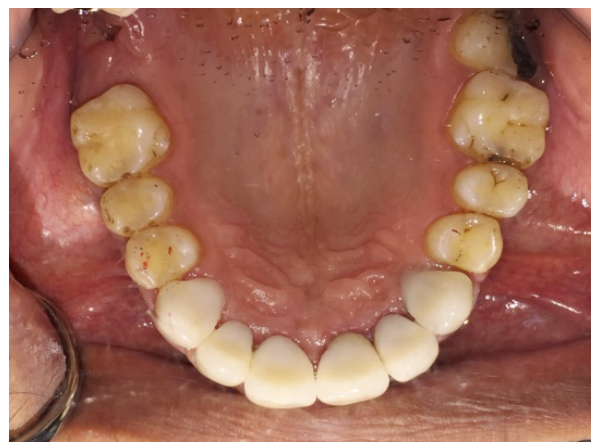

Figure 12: Palatal view of zirconia crowns.

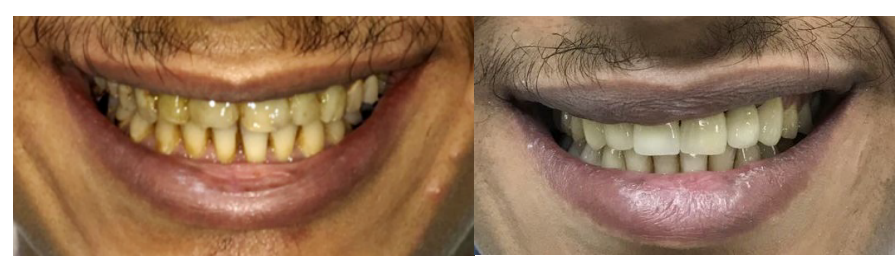

Figure 13: Pre and Post-operative view. 


\section{References}

1. Guazzato M, Proos K, Quach L, Swain MV (2004) Strength, reliability and mode of fracture of bilayered porcelain/zirconia (Y-TZP) dental ceramics. Biomaterials 25 : 5045-5052. [Crossref]

2. Eschbach S, Wolfart S, Bohlsen F, Kern M (2009) Clinical evaluation of all-ceramic posterior three-unit FDPs made of In-Ceram Zirconia. Int J Prosthodont 22: 490-492. [Crossref]

3. Guess PC, Schultheis S, Bonfante EA, Coelho PG, Ferencz JL, et al. (2011) Allceramic systems: laboratory and clinical performance. Dent Clin North Am 55: 333352. [Crossref]

4. Vult Von Steyern P (2005) All-ceramic fixed partial dentures. Studies on aluminum oxide and zirconium dioxide based ceramic systems. Swed Dent J 173: 1-69. [Crossref]

5. Kern M, Wegner SM (1998) Bonding to zirconia ceramic: adhesion methods and their durability. Dent Mater 14: 64-71. [Crossref]

6. Piconi C, Maccauro G (1999) Zirconia as a ceramic biomaterial. Biomaterials 20: 1-25. [Crossref]

7. Covacci V, Bruzzese N, Maccauro G, Andreassi C, Ricci GA, et al. (1999) In vitro evaluation of mutogenic and carcinogenic power of high purity zirconia ceramic. Biomaterials 20: 371-376. [Crossref]
8. Agustín-Panadero R, Fons-Font A, Roman-Rodriguez JL, Granell-Ruiz M, del RioHighsmith J, Sola-Ruiz MF (2012) Zirconia versus metal: a preliminary comparative analysis of ceramic veneer behavior. Int J Prosthod 25: 294-300. [Crossref]

9. Wang X, Fan D, Swain MV, Zhao K (2012) A systematic review of all-ceramic crowns: clinical fracture rates in relation to restored tooth type. Quintess Int 25: 441-450. [Crossref]

10. Al-Amleh B, Lyons K, Swain M (2010) Clinical trials in zirconia: a systematic review. J Oral Rehabil 37: 641-652. [Crossref]

11. Ortorp A, Kihl ML, Carlsson GE (2012) A 5-year retrospective study of survival of zirconia single crowns fitted in a private clinical setting. J Dent 40: 527-530. [Crossref]

12. Beuer F, Stimmelmayr M, Gernet W, Edelhoff D, Güh JF, et al. (2010) Prospective study of zirconia-based restorations: 3-year clinical results. Quintessence Int 41: 631637. [Crossref]

13. Poggio CE, Dosoli R, Ercoli C (2012) A retrospective analysis of 102 zirconia single crowns with knife-edge margins. J Prosthet Dent 107: 316-321. [Crossref]

14. Rinke S, Schäfer S, Lange K, Gersdoff N, Roediger M (2013) Practice-based clinical evaluation of metal-ceramic and zirconia molar crowns: 3 year results. J Oral Rehabil 40: 228-237. [Crossref]

Copyright: (C2017 Ahmad M. This is an open-access article distributed under the terms of the Creative Commons Attribution License, which permits unrestricted use, distribution, and reproduction in any medium, provided the original author and source are credited. 